\title{
LOS JÍCAROS SECRETOS DE VILHELM HARTMAN
}

\author{
Carlos Villalobos Villalobos*
}

Ha pasado más un siglo. Carl Vilhelm Hartman está muerto y su última voluntad sobre este tema fue el silencio. No lo culpo. En su época se hubiera requerido demasiado valor para revelar lo que sabía. Pero yo no quiero llevarme a la tumba esta información. Por mis propios medios descubrí lo que el viejo Hartman se traía entre manos. Seguí sus pistas paso a paso y tengo pruebas contundentes. Sé que esto asombrará a la Ciencia e inquietará a la humanidad entera, pero estoy seguro de que el mundo ya está listo para saberlo.

Tenía referencias de Vilhelm Harman gracias a algunas alusiones que hay de él en los libros de arqueología costarricense, pero la razón que me hizo retornar a sus escritos y a sus pasos no tiene conexión directa con esta rama del saber, sino con algo muy secreto y poderoso que él sabía. Poco a poco lo iré contando todo. Por ahora inicio este informe con el dato de que esto empezó por casualidad una noche en San José. Había ido a un bar con la intención antropológica de conocer a alguna mujer bonita y experimentar con ella algún acercamiento etnográfico in situ. $\mathrm{Y}$ esa noche se puso en mi camino una informante de pelo largo y negro, cara bella y pechos grandes llamada Amaranda. La invité a un trago y charlamos. Me contó que era oriunda de Jicaral de Puntarenas y que allá en el pueblo, en la casa de su madre, había dejado un hijo que tenía apenas diez años. Pregunté por el papá del muchacho. "Si mi hijo tuviera padre- respondió- yo no tendría que andar en esto”. Me llamó la atención ese dato: ¿Un hijo sin padre? ¿Cómo es posible? Le pedí que por favor me lo explicara bien, que no lograba entender cómo pudo haber sucedido tal suceso. Amaranda se rió, me trató de idiota, se tomó su trago y luego me confesó al oído: "Es que me embarazó un palo de jícaro".

Tal vez algo así fue lo que le pasó a Carl Vilhelm Hartman, quizá conversó igual que yo con una muchacha hermosa de estos lados y quizá por eso se obsesionó con locura e hizo todo lo que hizo. Amaranda no me dio más datos esa noche. Pero al día siguiente, cuando regresé a la lucidez, luego de la resaca, en mi corazón estaba ella y dando vueltas de curiosidad me mordía el dato del jícaro que la había embarazado.

Ahora que ya he sacando conclusiones y he comparado todas las pruebas científicas que expondré en este informe, estoy seguro de que viejo Carl Vilhelm Hartman sabía de esta extraña propiedad embarazadora del jícaro, pero no se atrevió a hacerlo público. No lo juzgo, en este momento había demasiado machismo en el mundo y, seguramente, si hubiese publicado su investigación, lo habrían amenazado de muerte y quizá la historia contaría ahora que murió de un anónimo balazo en alguna de las ruinas arqueológicas de Centroamérica. Había venido a Costa Rica en 1896 financiado por la Sociedad Antropológica y Geográfica de Suecia. Se le terminaron las razones oficiales y aún así regresó

* Escritor y profesor catedrático Universidad de Costa Rica. Recepción: 04/09/12. Aceptación: 06/09/12. 
una y otra vez. Evidentemente andaba detrás de algo fascinante. Decía que era arqueólogo y para demostrarlo escribió tratados, entre los que destaca una monografía de 1901 llamada Archaeological Researches in Costa Rica. Pero esta era su coartada. ¿A quién engañaba? Hartman en realidad era botánico. Eso fue lo que estudió en Suecia cuando joven. Con su sombrero negro y el porte misterioso con el que aparece siempre en las fotos que le tomaron, este viejo zorro no era lo que decía ser. Su verdadero interés estaba en ese fruto que cuelga de los árboles como un testículo de toro y que aquí llamamos jícaro y en algunas partes llaman güira, guaje cirial, hayal y en otras taparo, totuma, totumo y hasta morro.

Carl Vilhelm Hartman era experto las espermatófitas, una de las más importantes divisiones del reino vegetal. (Nótese la conexión con el origen de la palabra espermatozoide) Así que con toda propiedad científica este viajero describió el arbusto. Sabía muy bien que pertenecía a la familia de los bignoniaceae y específicamente a la especie Crescentia alata y habló con admiración de las redondas formas que cuelgan de los árboles, pero no se atrevió a decir el secreto que ahora, con pruebas contundentes, yo voy a develar.

Amaranda estaba metida en mis cavilaciones. Quería verla de nuevo: el extraño secreto que me confió me daba vueltas. ¿Cómo podría ser posible que un ser vegetal tuviera propiedades embarazadoras? No. Eso es imposible, pensé. Y estuve a punto de descartar la hipótesis y aceptar que me había visto la cara de tonto y me engañaba. Pero entonces, como suele pasar con los grandes descubrimientos de la historia, un chispazo científico me iluminó. Fue como la manzana en la cabeza de Newton. Hay una historia maya que habla de un árbol que embaraza a una princesa. Lo recuerdo porque cuando la Liga Maya todavía estaba en San José yo iba de vez en cuando a oír sus charlas. Necesitaba, como corresponde, corroborar el dato. Fui a la biblioteca y solicité el Popol Vuh. Lo leí con devoción científica. Mi memoria no me había fallado. Ahí estaba el dato, justo en el capítulo tercero de la segunda parte. Y lo más impresionante, casi doy un grito en la sala de lectura, el árbol era de jícaro. ¿Casualidad? Los hombres de la aldea habían colgado las cabezas de unos guerreros en un jícaro y las calaveras eran como frutas y asombraban a todos. Ixquic, la princesa, oyó la historia y quiso ir a ver, pero su padre no la dejaba. Esta es la cita de lo que ella dijo y acto seguido hizo:

- ¿Por qué no he de ir a ver ese árbol que cuentan?, exclamó la joven. Ciertamente deben ser sabrosos los frutos de que oigo hablar. A continuación se puso en camino ella sola y llegó al pie del árbol que estaba sembrado en Pucbal-Chah.

El Popol Vuh es el libro de la historia sagrada maya y por lo tanto de mucho respeto milenario, y según se narra aquí, el árbol de jícaro soltó una sustancia que le cayó encima a la muchacha y de este modo quedó embarazada. Ixquic tuvo gemelos que nacieron y crecieron sanos y llegaron a ser valientes guerreros y notables héroes de la historia maya. ¿Por qué Ixquic quería ir y cómo es que sabía que los frutos del jícaro debían de ser sabrosos? Es claro que hay un guiño erótico en este juego, de lo que se infiere que las mujeres, ante el llamado de la vida, y a falta o rechazo del macho, encuentran atractivo el árbol del Crescentia alata.

Ahora entiendo por qué un experto en plantas espermatófitas se interesó tanto por la arqueología. Hartman había estado muchas veces en comunidades indígenas en el sur de México y Guatemala. Evidentemente leyó el Popol Vuh y supo lo que supe yo. Notó de seguro este guiño erótico y se acordó de la muchacha cuyo hijo no tenía padre. Comprendo ahora por qué siguió viniendo a Centroamérica. Buscaba más pistas y por eso dirigió importantes excavaciones en la región. Pruebo de este modo, que el viejo Hartman creyó que en los yacimientos arqueológicos podría hallar mayores datos. Es muy probable que los encontrara, pues fueron muchos años de paciente búsqueda.

En cuanto tuve este primer dato fui con el corazón el vilo a buscar a mi Amaranda y la encontré triste como el día en que la conocí: echaba de menos a su hijo sin padre. La invité de nuevo a un trago y le conté la historia de 
Ixquic. Se puso alegre. Se rió y no paraba de reír. Le prometí que no iba a concluir ahí mi investigación, que por esta, e hice la señal de la cruz, iba a seguir hasta demostrarle al mundo que su explicación del hijo sin padre era científicamente comprobable.

Seguramente por eso Carl Vilhelm Hartman estaba literalmente enamorado de Costa Rica o al menos de una de sus mujeres. Imagino que iba a buscar a su Amaranda o como se llamase y, claro, con ella el viejo sí compartía los descubrimientos. Si no hubiera pasado un siglo, estoy seguro que doy con esa mujer, pero es mucho tiempo y es imposible que viva, salvo que el jícaro también posea propiedades para hacer que retorne la juventud, pero sobre esto sí que no hay ningún indicio, al menos hasta donde yo he llegado.

Seguí adelante con mis investigaciones. En la biblioteca pedí una enciclopedia y el Diccionario de la Real Academia Española. Averigüé de este modo que la palabra "jicarazo", en su segunda acepción es "propinación alevosa de veneno”. ¿Por qué veneno, si el jícaro no es una planta venenosa? Curioso, ¿verdad? Mi hipótesis de trabajo es la siguiente: nuestros antepasados ya sabían del peligroso poder del jícaro. Los indígenas, que eran sabios botánicos, supieron de esta virtud de empreñación, pero no se atrevieron a decirlo abiertamente, después de todo eran varones. Y fue por eso que difundieron la creencia de que el árbol era venenoso, un dato claramente falso. Y fue así como se creó esta curiosa y yo diría sospechosa expresión vernácula que finalmente fue recogida por los académicos de la lengua. Como conjetura científica pienso que tal vez el propio Carl Vilhelm Hartman tuvo que ver en esto, después de todo él había tenido informantes indígenas de primera mano. Así que él mismo pudo haber recogido esta acepción y perfectamente, gracias a sus contactos académicos en el mundillo de Europa, bien pudo haber influido en la Academia. Nótese que es una advertencia, es decir, un mensaje oculto puramente precautorio. ¿Quién sino Hartman sabía de esto?

Revisé también si en otras culturas había historias similares. Leí a Mircea Eliade, Lévi
Strauss y diccionarios de mitología. Yo sé que los mitos son mitos, pero tienen una base real y esa prueba ya la tenía en la cultura maya. A veces cuando se me nubla la mente y el ánimo se quiebra y no hay pastilla que lo arregle, me ayuda mucho leer la Biblia. Fue así como estando de mis pesquisas, me llamó la atención el Génesis y específicamente este pasaje que copio textualmente:

Y Jehová hizo nacer de la tierra todo árbol delicioso a la vista, y bueno para comer; también el árbol de la vida en medio del huerto, y el árbol de la ciencia del bien y del mal (Génesis:1:9).

Veamos con lupa este pasaje. Si se analiza bien hay aquí cuatro tipos de árboles: Uno: los árboles deliciosos a la vista. Dos: los árboles buenos para comer. Tres: el árbol de la vida. Y cuatro: el árbol de la ciencia del bien y el mal. Ahora bien, las tipología uno y dos son conocidas, pues se trata de los árboles de adorno como el corteza amarilla y los frutales, como el naranja. Pero hay dos tipologías más que se mencionan. El árbol de la ciencia, que estaba disfrazado de manzano y que ya se sabe era el prohibido. Sobre esto muchos teólogos $\mathrm{y}$ hermeneutas han hablado y hablado y no corresponde entrar en detalle. Y ahora viene lo sorprendente, lo que yo califico como el más grande descuido en la historia de la explicación bíblica. Adán y Eva en realidad nunca comieron frutos del árbol de la vida. Solo lo hicieron del árbol de la Ciencia y eso fue lo que enojó a nuestro Creador. Queda clarísimo entonces que Dios sembró un árbol de la vida. La pregunta sería entonces, ¿desapareció esta especie? ¿Qué relación tiene ese árbol con los que encontraron los mayas? ¿Es acaso la misma especie que dejó embarazada a mi Amaranda? Bíblicamente no hay ninguna razón para suponer que Dios destruyó ese árbol. Yo casi no soy creyente y no quiero usar esto como axioma de fe, para nada. Dado que este es un informe científico, debo decir que lo importante es el fundamento del mito, igual que en el caso de la cultura maya. De esto modo, esta fuente de información es válida y no corresponde rechazarla por prejuicio religioso. Se trata de una ficha clave que calza perfectamente en este rompecabezas. 
No sé si Carl Vilhelm Hartman era creyente, pero él tenía una cultura sólida y estoy seguro de que él también encontró esta pista bíblica y que ese día, al igual que yo, corrió donde su Amaranda a contarle todo. Y seguramente ella también se rió como rió conmigo esa noche mi buena amiga de Jicaral.

Con gran pasión leí y releí la Biblia tratando de averiguar si en algún otro punto se hace referencia a este árbol, pero por algún descuido de los profetas no se menciona tal asunto. Pero un libro bastante cercano a la fe cristiana como es el Libro de Mormón sí incluye una referencia. En Nefi 8:10 hay un pasaje muy sospechoso. Dice así: "Y sucedió que vi un árbol cuyo fruto era deseable para hacer a uno feliz". Luego continúa Nefi contando que el fruto era blanco y que algunos se avergonzaban y se perdían luego de probarlo. ¿Qué significa todo esto? O hay un tipo nuevo de árbol que deberíamos llamar el palo de la felicidad, o se trata de la misma familia bignoniácea que he venido describiendo. Creo que se trata de la misma especie. Tengo dos razones para creerlo: la primera es que hay una referencia al color blancuzco del fruto: quizá Nefi se refería propiamente a la sustancia lechosa y esto, es muy obvio, coincide con el color natural del semen; y la segunda razón es que algunos de los que probaban el fruto se sentían avergonzados. ¿Por qué? Buena pregunta...

Mi descubrimiento resolverá el drama que viven las muchachas cuando tienen que hablar con a sus padres de un embarazo sin pareja oficial. Ahora podrán hacerlo como si narraran un cuento o el último chiste de la calle. Bien podrían decir: "Papá, se va a matar de la risa con lo que le voy a contar. Hace un mes me escupió un palo con así jícaras y la semana pasada no me vino la regla". Gracias a este aporte científico mío, de este modo, las familias van a vivir más felices y la historia de los escándalos sexuales habrá pasado para siempre a las lápidas de la historia. Es curioso que Carl Vilhelm Hartman no pensara en esto y se llevara consigo a la tumba el secreto. Yo imagino que seguro sí lo tomó en cuenta, pero quizá tuvo claro de que aún el mundo no estaba listo para entenderlo y decidió esperar a que en el futuro alguien más, es decir alguien como yo, lo supiera justo en un momento adecuado para la especie humana.

Por otra parte, científicamente está probado que los varones en el mundo somos cada día menos productores de semen. Así las cosas en unos cuantos años algunos seremos inevitablemente estériles. Hay diversos estudios hechos con seriedad y todos apuntan a la misma evidencia. El debilitamiento de los varones es innegable e inevitable. Dios es sabio: el árbol lechoso que yo he descubierto, gracias a la inspiración antecesora de Hartman, es la gran solución en caso de que esta teoría feminista sea cierta y las investigaciones médicas no estén equivocadas. Confieso que al recordar este dato me sentí bastante presionado, pues si no me apuraba con la investigación, la humanidad podría desaparecer. El fin del mundo bien podría evitarse gracias a estas divulgaciones que escribo aquí. Yo seré, lo puedo ver con claridad el salvador del mundo. Posiblemente los hijos de este semen vegetal que existe desde la Creación, me agradezcan la vida y quizá algún parque en el futuro lleve mi nombre, escrito con jícaras en una loma, así como ahora se ve de lejos el letrero de Hollywood allá en los Ángeles de California. Al respecto yo quisiera, por justicia histórica, que no sea mi nombre el que aparezca ahí. Yo pido que sea más bien el nombre de Carl Vilhelm Hartman. A mí me basta con el amor desbordado de mi Amaranda y ser bienvenido cualquier lugar: es todo lo que pido.

Al sur de México existe una tradición que seguramente Carl Vilhelm Hartman conoció: la gente mueve jícaras para revolver el muzú o shish del pozol. Este movimiento es conocido como el meneadito de la jícara o el meneadito pozolero. Advierto en esta costumbre, claramente erótica, es otra prueba, otra pieza que calza como confirmación de que por donde se le mire todo lleva a la misma conclusión: el jícaro es erótico y fue creado para procrear.

Ahora bien, el último paso para coronar esta investigación será conseguir una muchacha, inseminarla con el semen del jícaro y ver el resultado. Para algo así se requiere el equipo médico de un ginecólogo y desde luego una 
mujer dispuesta a tener un hijo sin padre. Desgraciadamente no poseo los medios adecuados y aunque los tuviera no es tan fácil conjuntar ambos requisitos. Fue entonces cuando se me ocurrió una idea magistral. Posiblemente a Carl Vilhelm Hartman le pasó por la mente lo mismo y al igual que yo esa noche corrió en busca de su mujer. En cuanto vi a mi Amaranda le lance sin más ni más mi propuesta. "Vengo a que usted se case conmigo y que tengamos un hijo con un palo jícaro, no me importa, no soy celoso de los árboles". Hubo un silencio kilométrico y luego como queriéndose escapar me dijo que yo estaba loco, la alcancé y la agarré de un brazo. Le hice prometerme que lo iba a pensar. Entonces me prometió que sí, que lo pensaría. Esa noche tomé ilusionado y brindaba con todo el mundo por hijo sin padre que pronto nacería. En cuanto el hijo del jícaro nazca el paso siguiente consistirá en hacerle una prueba de ADN y listo.

El futuro el Crescentia alata, estoy seguro, será llamado por la comunidad científica Crescentia seminalis o quizá Hartmania seminalis en honor al científico sueco que honro en mis escritos. Actualmente la planta está distribuida por varios sitios en el mundo. En México hay una playa llamada Jicaral y en León de Nicaragua hay otro pueblo con el mismo nombre. Hay amplias posibilidades para que las mujeres de todo el mundo vengan en peregrinación sagrada a restregarse la piel contra la cascara del Crescentia.

En 1983, el aleman Karsten Jochim instaló en Nicaragua una planta procesadora de jícaras, según su versión oficial, para obtener etanol y otros productos. No dijo el muy astuto qué otros productos eran los que buscaba, pero yo creo saberlo ahora. Según se sabe, pronto desistió de su empresa y no quiso divulgar los resultados. En 1989 el austríaco Nikolaus J. Foidl retomó el proyecto. Esto prueba que hay gente en el mundo que algo sabe de los poderes de este árbol sagrado. No sé si Jochim o Foidl lograron inseminar a alguna mujer o si más bien se llevaron la sorpresa de que sus propias mujeres de repente quedaron embarazadas $\mathrm{y}$, claro, al hacer la prueba de la paternidad, el árbol del jícaro era el responsable y esto los avergonzó profundamente. Quizás por eso es que ambos desistieron de la idea y no se les hizo hacer historia. Así las cosas, me corresponde a mí el honor de hacerlo público. Y está bien que así sea, porque ya es hora de que me empiecen a suceder cosas buenas en la vida.

Cuando nazca el hijo sin padre que pronto le habrá de nacer a mi Amaranda, quiero que lo bauticemos con el hermoso nombre Vilhelm, en homenaje al viejo Hartman. Estaba casi seguro de que con esta nueva mi Amaranda me diría que sí. Regresé entusiasmado en busca de la jicaralense. Pero esa noche no llegó a su puesto de trabajo, ni la siguiente y nadie supo darme razones en el lugar. Más aún, me prohibieron entrar al sitio, el del bar me gritó que Amaranda no había vuelto por ahí por culpa mía, que qué carajos le había dicho que la tenía tan asustada. Eso no puede ser posible. Eso lo inventó el del bar por celos porque se dio cuenta de mi intención matrimonial y quizá incluso de mi descubrimiento y el cobarde tiene miedo de que en el futuro las mujeres prefieran el jícaro y lo desprecien a él. Por estúpido se merece que le pase algo así. Y por esta razón, también, es que escribo y hago público este informe. Para que de vez una por todas las mujeres sepan que existen alternativas a tipos tan despreciables como este.

Por dignidad no volveré a ese bar, aunque extraño a Amaranda y me duela su ausencia. Tal vez un día de estos, cuando este informe se divulgue, ella regrese arrepentida y acepte mi propuesta. Cuando este descubrimiento recorra el mundo y los periódicos pongan mi foto en primera plana, ya verán el estúpido del bar y los de todos los bares de donde me han echado, la sorpresa mundial que provocará la revelación de todo esto. Si Carl Vilhelm Hartman estuviera vivo esta noche se iría a emborrachar conmigo. 
